\title{
Nontarget Embolisation or Local Effect of Infarction?
}

\author{
Jules David Dyer
}

Received: 25 February 2013/ Accepted: 24 March 2013/Published online: 15 May 2013

(C) Springer Science+Business Media New York and the Cardiovascular and Interventional Radiological Society of Europe (CIRSE) 2013

\section{To the Editor}

I read with interest the account of a patient who had a perforation of her transverse colon 3 months after uterine artery embolisation. At laparotomy, she was discovered to have a necrotic left fallopian tube and ovary and a perforation of the midtransverse colon. The authors concluded that the risk of colonic injury should be borne in mind if there are large subserosal fundal fibroids in close proximity to the transverse colon. "If embolisation is performed knowingly, taking into account all of the treatment options in such cases, evidence of bowel complications must be carefully sought.... Even if imaging is unremarkable, exploratory laparotomy may be advisable sooner rather than later" [1].

I believe that the evidence from this single case is inadequate to draw such major conclusions. The midtransverse colon (which is mobile) is frequently close to a fibroid. The more likely mode of injury given of nontarget embolisation does not depend on the closeness of the colon to the fibroid. Early laparotomy for abdominal pain despite normal imaging has complications and consequences of its own.

Conflict of interest None

\section{References}

1. Acharya J, Bancroft K, Lay J (2012) Perforation of transverse colon: a catastrophic complication of uterine artery embolisation for fibroids. Cardiovasc Intervent Radiol 35:1524-1527

J. D. Dyer $(\bowtie)$

Radiology Department, New Cross Hospital, Wolverhampton,

West Midlands WV10 0QP, UK

e-mail: Jules.Dyer@nhs.net 